\title{
Erratum to: Thrombocytosis and immunohistochemical expression of connexin 43 at diagnosis predict survival in advanced non-small-cell lung cancer treated with cisplatin-based chemotherapy
}

Gangjun Du $\cdot$ Yiming Yang $\cdot$ Yaping Zhang $\cdot$

Ting Sun - Weijie Liu $\cdot$ Yingying Wang

Jiahuan Li $\cdot$ Houyun Zhang

Published online: 17 May 2013

(C) Springer-Verlag Berlin Heidelberg 2013

Erratum to: Cancer Chemother Pharmacol (2013)

71:893-904

DOI 10.1007/s00280-013-2080-6

In the original article, one of the co-author's (Yiming Yang) given name has been published incorrectly. The correct given name should be Yiming.

The online version of the original article can be found under doi:10.1007/s00280-013-2080-6.

G. Du (凹) · Y. Zhang · T. Sun · W. Liu · Y. Wang · J. Li

Institute of Pharmacy, Pharmacy College of Henan University, Jinming street, Kaifeng 475004, Henan, China

e-mail:kfdgj@sohu.com

Y. Yang $(\varangle) \cdot$ H. Zhang

Department of Oncology, Kaifeng Second People's Hospital,

Bianjing street, Kaifeng 475001, Henan, China

e-mail: yangymch@sina.com 